\title{
Analysis of Failed Nuclear Plant Components*
}

D. R. Diercks

\author{
Materials and Components Technology Division \\ Argonne National Laboratory \\ Argonne, IL 60439 USA.
}

July 1992

\section{DISCLAIMER}

\begin{abstract}
This report was prepared as an account of work sponsored by an agency of the United States Government. Neither the United States Government nor any agency thereof, nor any of their employees, makes any warranty, express or implied, or assumes any legal liability or responsibility for the accuracy, completeness, or usefulness of any information, apparatus, product, or process disclosed, or represents that its use would not infringe privately owned rights. Reference herein to any specific commercial product, process, or service by trade name, trademark, manufacturer, or otherwise does not necessarily constitute or imply its endorsement, recommendation, or favoring by the United States Government or any agency thereof. The views and opinions of authors expressed herein do not necessarily state or reflect those of the United States Government or any agency thereof.
\end{abstract}

To be presented at Materials Week '92. November 2-5, 1992, Chicago and published in the Proceedings of the Session on Failure Analysis

"Work supported by Commonwealth Edison Company under ACK 85026 


\begin{abstract}
Argonne National Laboratory has conducted analyses of failed components from nuclear power generating stations since 1974. The considerations involved in working with and analyzing radioactive compenents are reviewed here, and the decontamination of these components is discussed. Analyses of four failed components from nuclear plants are then described to illustrate the kinds of failures seen in service. The failures discussed are (a) intergranular stress corrosion cracking of core spray injection piping in a boiling water reactor, (b) failure of canopy seal welds in adapter tube assemblies in the control rod drive head of a pressurized water reactor, (c) thermal fatigue of a recirculation pump shaft in a boiling water reactor, and (d) failure of pump seal wear rings by nickel leaching in a boiling water reactor.
\end{abstract}

APPROXIMATELY 113 NUCLEAR ELECTRICAL POWER GENERATING PLANTS are presently operating in the United States with a combined generating capacity of 106,905 MWe. In 1990, they generated $20.6 \%$ of the nation's electrical energy demand (1). Component failures occur from time to time in these plants, and the rigorous inservice inspection procedures to which the plant components are subjected often result in the detection of flaws or other incipient failure processes before actual component failurc has occurred. As with any major technology, determination of the cause of failure is important in developing remedial actions to prevent future similar failures and thus improve plant reliability and safety.

Argonne National Laboratory (ANL) has conducted analyses of failed nuclear components since 1974. During that time, several dozen analyses have been performed, and considerable experience has been gained in the procedures for working with and analyzing these components and in the types of failures commonly observed in nuclear power plants.
The considerations and precautions required in working with these components will be summarized here, and a few representative failures will be described.

\section{Radioactivity Considerations}

The principal feature of components from nuclear power plants that sets them apart from other failed components is the likely presence of radioactive contamination. In virtually all cases, the failed components come from areas of the plant that receive no significant neutron radiation from the reactor core, so no bulk activation of the component has occurred. Contamination instead results from the deposition on component surfaces of radioactive isotopes that have previously been activated in the reactor core. In the typical sequence of events (2), corrosion products from reactor coolant piping, feedwater heaters, valve trim and other upstream cooling-circuit components are carried by the coolant into the reactor core, where they are activated by neutrons from the core to form radioactive nuclides. Radioactive contamination of downstream components occurs when particles of these activated corrosion products are deposited on the component surfaces or when oxides growing on the component surfaces incorporate activated metallic ions dissolved in the coolant.

As a result of this process, the radioactive contamination present on the surfaces of nuclear reactor cooling-circuit components typically consists of a complex mixed oxide made up primarily of transition metal spinels. The principal radionuclides present in this surface layer typically include ${ }^{58} \mathrm{Co},{ }^{60} \mathrm{Co},{ }^{11} \mathrm{Cr},{ }^{55} \mathrm{Fe},{ }^{59} \mathrm{Fe},{ }^{54} \mathrm{Mn},{ }^{63} \mathrm{Ni}$, and ${ }^{65} \mathrm{Zn}$. Of these, ${ }^{60} \mathrm{Co}$ is by far the most important, emitting intense gamma radiation at energies of 1.17 and $1.33 \mathrm{MeV}$ and having a relatively long half-life of $5.27 \mathrm{yr}$. It is not surprising, then, that ${ }^{60} \mathrm{Co}$ radiation accounts for approximately $80 \%$ of the exposure received by U.S. nuclear plant workers during operation, inspection, and maintenance 
activitics (3). This radionuclide also normally accounts for the bulk of the radioactivity present on failed components.

On rare occasions, contamination by radionuclides emitting alpha radiation may also be present on components. This condition generally indicates contamination from the nuclear fuel and its daughter products. Because alpha emitters can pose a significant health hazard if ingested, components with significant alpha contamination require remote handling in a glovebox or hot cell. Fortunately, such components are seldom encountered in nuclear power plant failure analyses.

\section{Component Decontamination}

Because the radioactive contamination present on nuclear plant components is normally caused by surface deposits rather than bulk activation, decontamination is essentially a matter of removing these surface deposits. Component decontamination is desirable both from the standpoints of reducing personnel exposure to radiation and of reducing the likelihood of subsequent contamination of laboratory space and equipment. In failure analysis, the need to decontaminate the failed component must always be balanced against the desirability of retaining as much information as possible related to the cause of failure.

Radioactive contamination is normally present in two forms, loose (or smearable) and fixed. Loose contamination is that which can be readily transferred to a cloth or other material wiped across the surface of the contaminated component, while fixed contamination cannot be readily removed in this manner. Fixed contamination generally produces most of the radiation field, and therefore most of the potential personnel radiation exposure, associated with a contaminated component. However, loose contamination poses the greatest hazard for secondary contamination of personnel and equipment. In general, the goal of decontamination is essentially to eliminate the loose contamination and reduce the fixed contamination to as low a level as practical. Complete elimination of radioactive contamination is usually not practical or even possible without severely damaging or destroying the surfaces of the component to be analyzed.

The general approach that we have taken to component decontamination is to use as gentle a procedure as possible in order to minimize damage to the physical evidence related to the failure cause. In many cases, scrubbing or ultrasonic cleaning of the component surfaces with detergent and water essentially eliminates loose contamination and substantially reduces the overall contamination level. Frequently, the component can then be sectioned to isolate the regions of interest, and the consequent reduction in the volume of material being handled results in acceptably low values of fixed contamination for subsequent examinations. Where decontamination cannot be accomplished in this fashion, commercially available buffered acid decontaminating solutions, sometimes used sequentially with oxidizing permanganate solutions, are used in the scrubbing or ultrasonic cleaning procedure instead of detergent and water. In rare situations, dilute $\mathrm{HCl}$ or $\mathrm{HNO}_{3}$ is used to dissolve persistent contaminant surface oxide films, but this treatment almost always results in some damage to the underlying component surface.

Laboratory personnel are required to wear radiation monitoring devices when working with radioactive nuclear components. The success of our decontamination procedures is borne out by the levels of radiation received by our personnel as measured by these devices. U.S. Department of Energy regulations permit radiation workers to receive a maximum whole body radiation exposure of $5000 \mathrm{mrem} / \mathrm{yr}$. However, ANL has set an administrative limit of 1500 $\mathrm{mrem} / \mathrm{yr}$ as the maximum exposure. Annual doses received by personnel working with failed nuclear plant components consistently fall well below this $1500 \mathrm{mram} / \mathrm{yr}$ limit and, in many cases, do not greatly exceed the $360 \mathrm{mrem} / \mathrm{yr}$ average dose received by the general U.S. population from natural radiation sources and medical treatment (4).

\section{Examples of Nuclear Çomponent Failures}

Intergranular Stress Corrosion Cracking of Core Spray Injection Piping in a Boiling Water Reactor. Isolated incidents of intergranular stress corrosion cracking (IGSCC) of austenitic stainless steels in boiling water reactor (BWR) piping first began to occur in the late $1960 \mathrm{~s}$, shortly after the commercial introduction of this reactor concept (5). By the mid-1970s, the problem was recognized as both significant and generic to the BWR technology, rather than plant-specific (6). While the early incidents of pipe cracking involved the smaller $100-\mathrm{mm}$ (4-in.) diameter bypass lines and 250-mm (10-in.) diameter core spray lines, Danko (7) reported in 1982 that several incidents of cracking had occurred in $610-\mathrm{mm}$. (24-in.) and $710-\mathrm{mm}$ (28-in.) main recirculation piping and that a total of 287 incidents of IGSCC in BWR piping had been reported worldwide. Marston and Jones (8) placed the total number of incidents of IGSCC in BWRs at more than 1000 from 1974 through 1991.

It is well established that the occurrence of stress corrosion cracking requires the simultaneous presence of a susceptible material, a tensile stress, and a corrosive environment. In the case of IGSCC in BWR piping, these conditions are typically present in the heat-affected zone (HAZ) of Type 304 stainless steel base metal piping immediately adjacent to welds. Here, the thermal treatment associated with the welding process sensitizes the steel, i.e., it causes the precipitation of $\mathrm{Cr}$ carbides along the grain boundaries, with a consequent depletion of dissolved $\mathrm{Cr}$ in these regions and a resulting loss of corrosion resistance. In addition, the weld thermal treatment produces significant residual tensile stresses. The corrosive environment is provided by the relatively high dissolved-oxygen content of the reactor coolant water. 
Efforts to solve the problem have focused on all three of the contributing factors, and considerable progress has been made in controlling IGSCC in BWR pining. Several approaches have been demonstrated as effective, including the use of resistant materials, residual stress improvement to eliminate or reduce residual tensile stresses, and better control of water chemistry (8). The use of more resistant materials requires the replacement of susceptible Type 304 stainless steel with an alloy such as Type $316 \mathrm{NG}$ (nuclear grade) stainless steel, which has reduced carbon to prevent sensitization and increased nitrogen to compensate for the loss in strength caused by the carbon reduction. Mechanical or thermal processes can be used to place the inside surface of piping near welds into a state of residual compressive stress. Improved water chemistry control requires that the dissolvedoxygen content of the coolant water be reduced to well below the level of $0.2 \mathrm{ppm}$ (where IGSCC problems are most severe) by such measures as the injection of hydrogen (hydrogen water chemistry) (9). As operating BWR plants have put these preventative measures into practice, incidents of IGSCC have steadily declined.

A rather comprehensive failure analysis performed by the author approximately 10 years ago illustrates the general features of this type of failure, and it also includes some additional unique and interesting features. This analysis has been described in detail elsewhere (10), and only its general features will be repeated here.

The failure involved the $25-\mathrm{mm}$ (10-in.) diameter core spray injection piping from the Quad Cities Unit 2 BWR. This piping is used to inject coolant into the reactor pressure vessel in the event of a loss-of-coolant accident, and under normal operating conditions it is filled with more or less stagnant cooling water at a temperature of 205 to $260^{\circ} \mathrm{C}(400$ to $500^{\circ} \mathrm{F}$ ) and a pressure of $6.9 \mathrm{MPa}(1000 \mathrm{psi})$. In addition to wrought Type 304 stainless steel piping material, the affected portion of the loop included a $90^{\circ}$ elbow and an adjacent $15^{\circ}$ elbow (or "wedge"), both forged of Type 304 stainless steel. The weld filler metal was Type 308 stainless steel in all cases.

A pressure test of the reactor pressure vessel conducted approximately eight years after the plant was put into operation revealed a coolant leak near the region where the $90^{\circ}$ elbow and adjacent wedge were welded into the piping loop. A subsequent ultrasonic inspection indicated several cracks near the welds joining the wedge and elbow to each other and to the adjacent piping. The portion of the injection line that included the suspect elbow, wedge, and shon lengths of adjacent piping on either end was renioved from the reactor and sent to ANL for analysis.

After the component was decontaminated with a commercial buffered acid solution, the suspect weld regions were cut from the piping and split axially into semicircular pieces. Dye-penetrant examinations and radiographic inspection revealed the presence of approximately 40 cracks at the inner surface in the three circumferential weld regions examined. Virtually all of the cracks were in the base metal
HAZ of the forged elbow and wedge material on each side of the weld; no cracks were initially seen in the adjacent wrought piping. The large majority of the cracks extended longitudinally along the axis of the components, with lengths typically about 10 to $15 \mathrm{~mm}$ ( 0.4 to $0.6 \mathrm{in}$.). This axial crack orientation is unusual; IGSCC cracks typically extend circumferentially around the affected components in the $\mathrm{HAZ}$ because of the orientation of the residual and externally applied stresses. A few faint dye-penetrant indications were seen at the outer surface of the components, and at least three of these were believed to be associated with leaking through-wall cracks.

Selected regions containing cracks were cut from the larger pieces, sectioned through the thickness of the elbow or wedge, and examined by optical metallography. The cracks were found to be intergranular and highly branched, and the majority of the cracks stopped at the base metal/weld metal interface or extended only a short distance into the weld metal. These features are very typical of IGSCC in nuclear reactor components. However, radiographic examinations suggested that at least one longitudinal crack extended from the wedge base metal HAZ, completely through the circumferential weld metal (approximately $7 \mathrm{~mm}$ thick at the thickest location examined), and into the HAZ of the adjacent wrought piping base metal. This was confirmed by optical metallography, and it is believed to be the first reported incident in which an IGSCC crack in a nuclear component completely penetrated a weld. Weld metal is generally considered to be highly resistant to the propagation of IGSCC.

The other microstructural feature noted in the optical metallography was the presence of pronounced banding of delta ferrite along the axial direction of the forged elbow and wedge material. Stringers of delta ferrite paralleled the flow lines in the forged microstructure; 10 delta ferrite phase was observed in the pipe material, which was not forged. The delta ferrite stringers also paralleled the axial cracks in the elbow and wedge.

Samples of elbow, wedge, and pipe material near and 'away from the HAZ of the weld were tested for sensitization according to ASTM Procedure A 262, Practice A. As expected, all of the samples from the $\mathrm{HAZ}$ were found to be heavily sensitized, and all of the samples from outside the HAZ showed little or no sensitization. Other tests and analyses on the component material included chemical analyses of the pipe, wedge, elbow, and weld filler metal; delta ferrite determinations for the weld filler metal; microhardness measurements on the elbow material as a function of distance from the weld; and room-temperature tensile tests on the pipe and elbow material. None of these tests or analyses revealed anything out of the ordinary.

It was concluded that the elbow and wedge components failed by IGSCC, with the welding process sensitizing the Type 304 stainless stecl and providing the residual tensile stresses. The semistagnant nature of the coolant water in the core spray injection lines helped to ensure a high level of 
dissolved oxygen, thus increasing corrosivity with respect to IGSCC. It was further suspected that the axial banding of the delta ferrite stringers in the forged elbow and wedge components contributed to the axial orientation of the cracks.

Failure of Canopy Seal Welds in Adapter Tube Assemblies in a PWR Control Rod Drive Head. The problem of IGSCC in recirculation coolant system piping is peculiar to BWRs, because the dissolved oxygen content of the coolant in pressurized water reactors (PWRs) is normally much too low to support this failure mechanism. However, SCC failures, both transgranular and intergranular, can occur in both PWRs and BWRs under other sets of corrosive conditions. The failure described here provides an example of transgranular stress corrosion cracking (TGSCC) in a PWR component.

Portions of three control rod drive head adapter tube assemblies were removed from a PWR and sent to ANL because of suspected leaking cracks. Each assembly was approximately $200 \mathrm{~mm}$ ( 8 in.) in diameter and 250 to $460 \mathrm{~mm}$ (10 to $18 \mathrm{in}$.) long. Each included a heavy-walled cylindrical cap threaded to an externally threaded pipe or tube, both fabricated of Type 304 stainless steel, with a circumferential canopy weld sealing the joint between the two pieces. This weld provided the seal between the pressurized coolant at approximately $15.2 \mathrm{MPa}(2200 \mathrm{psi})$ and the outside environment. The seal welds were made by placing a consumable ring insert of Type 308 stainless steel weld metal between the base metals of the cap and tube and fusing the weld region with a gas tungsten arc process. The general configuration of these components and an enlarged view of the canopy seal weld region are shown schematically in Fig. 1. The leaking cracks were suspected to be at or near these welds.

Upon receipt of the components, a hole was drilled in each of the canopy seal welds, and samples of entrapped coolant were removed for chemical analysis. The region beneath one of the welds was dry, so high-purity water was injected through the drilled hole, allowed to remain in place for four days, and then removed for analysis. The heavily contaminated components were then decontaminated with a dilute aqua regia solution $\left(\mathrm{HCl}+\mathrm{HNO}_{3}\right)$ after commercial solutions failed to produce satisfactory results.

Analysis of the extracted coolant samples generally revealed high $B$ levels ( 400 to $1000 \mathrm{ppm}$ ) due to the $\mathrm{H}_{3} \mathrm{BO}_{4}$ added to the coolant for reactivity control. The high-purity water injected into the dry weld cavity was found to contain only $\approx 2 \mathrm{ppm} B$. The only other cations found in significant quantities in any of the samples were $\mathrm{Mn}, \mathrm{Na}, \mathrm{Ni}$, and $\mathrm{Si}$, all present at levels of $\approx 5 \mathrm{ppm}$ or less. The $\mathrm{Na}$ and Si detected may have been contaminants from the glass bottles used to contain the water samples. Among the anions analyzed, $\mathrm{Cl}^{-}$ was detected at levels of $<0.1$ to $0.75 \mathrm{ppm}$ and $\mathrm{SO}_{4}^{2+}$ at levels of 0.31 to $1.8 \mathrm{ppm}$.

Nondestructive examinations of the three components by dye-penetrant, ultrasonic, and eddy current techniques revealed

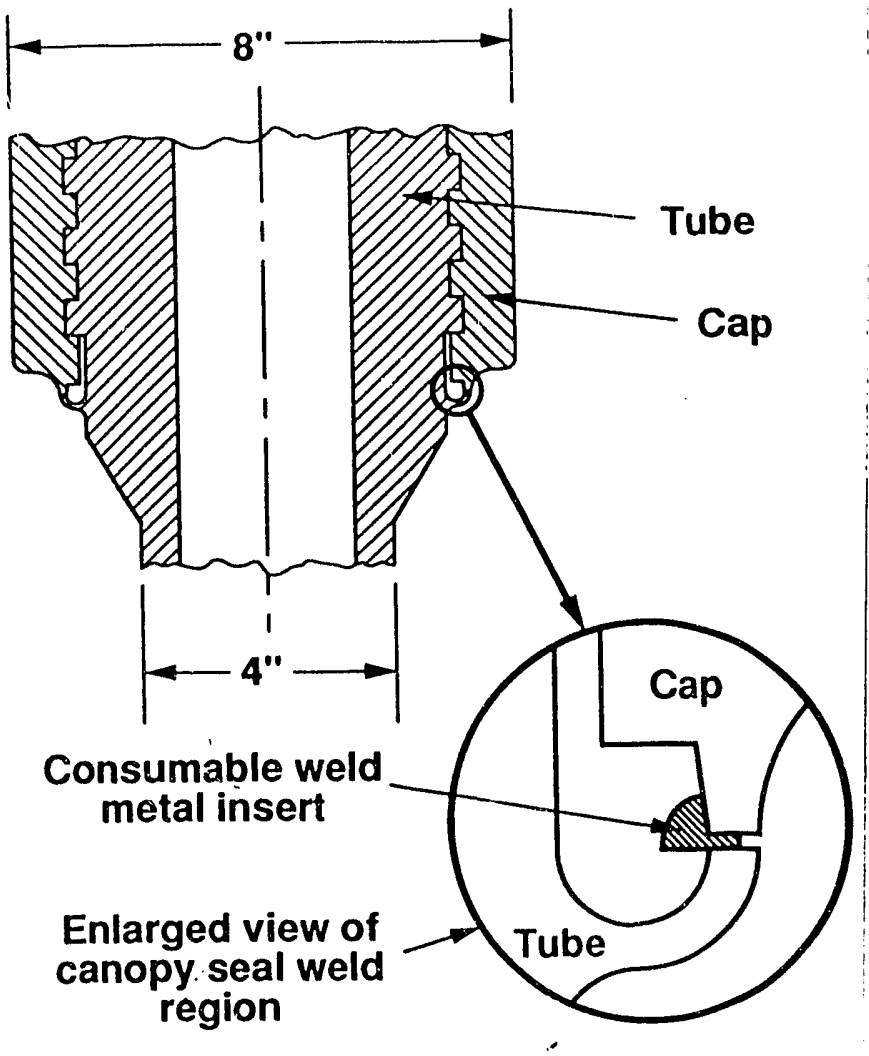

Fig. 1 - Schematic drawing of portion of control rod drive head adapter tube assembly, showing enlarged view of canopy seal weld region

several possible flaw indications in the weld regions, but none could be clearly identified. To facilitate $\mathrm{X}$-radiography and to permit subsequent metallographic examination, the circular weld regions were cut from all three components. $\mathrm{X}$-radiography by conventional and high-resolution microfocused techniques again revealed several possible flaw indications.

The nature of the failure was finally revealed by umetallography. In a normal canopy seal weld, the consumable weld metal insert is completely fused and blends smoothly into the adjacent base metal. In contrast, the appearance of a failed weld region is shown in Fig. 2 . The insert is incompletely fused, and a crack has initiated at the resulting crevice between the unfused portion of the insert and the tube base metal below the insert. This highly branched crack completely penetrated the weld metal at this point, resulting in a leak. Similar cracks were observed at other locations in the welds where incomplete fusion of the consumable insert produced a crevice or stress concentratc:

Figure 3 shows a location where a crack apparently initiated in the base metal in the crevice region rather than at the root of the crevice. This crack then grew transgranularly through the base metal and then through the adjoining weld metal. Minor attack of the unfused consumable metal insert opposite the main crack can also be seen in Fig. 3. 


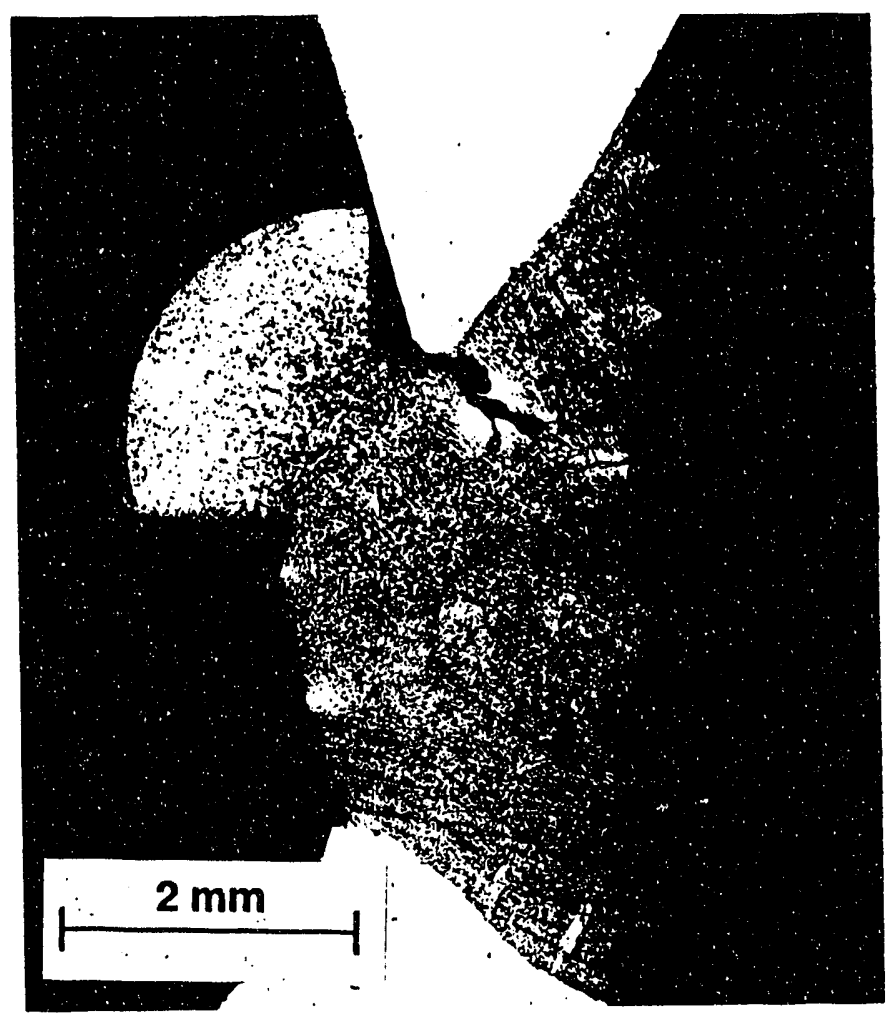

Fig. 2 - Appearance of failed weld region, with incomplete fusion of consumable weld metal insert

It was concluded that the observed crevices between the consumable weld metal inserts and the base metal were produced by failure to maintain the welding electrode exactly on the center line of the weld joint, thereby causing one side of the insert to be incompletely fused during the welding process. The resulting crevice provided a suitable environment for the buildup of corrosive species, particularly $\mathrm{Cl}^{-}$and $\mathrm{SO}_{4}^{2+}$, and also sometimes served as a point of stress concentration. These factors combined with the residual stresses from welding to cause the austenitic stainless steel base and weld metal to fail by TGSr.C. It has been shown that dissolved-sulfate levels as low as 0.1 to $1 \mathrm{ppm}$ can significantly accelerate stress corrosion cracking at 200 to $300^{\circ} \mathrm{C}\left(390\right.$ to $\left.570^{\circ} \mathrm{F}\right)$ in lightly sensitized austenitic stainless steels in the simultaneous presence of $0.2 \mathrm{ppm}$ dissolved oxygen (11). Dissolved-oxygen levels are normally much lower than this in PWR coolant systems, but higher levels of both oxygen and $\mathrm{Cl}^{-}$and $\mathrm{SO}_{4}^{2+}$ can develop in crevices. The aggressive environment that was present in the crevices is indicated by the apparent attack of the unfused consumable weld metal insert opposite the main crack.

TGSCC from another cause was also observed in one of the components. An indentation resulting from an apparent hammer blow was present at one location on the outer surface of the weld region of the component, and cold work and TGSCC was observed in the underlying base metal. Here, the cold work from the impact blow and the resulting high

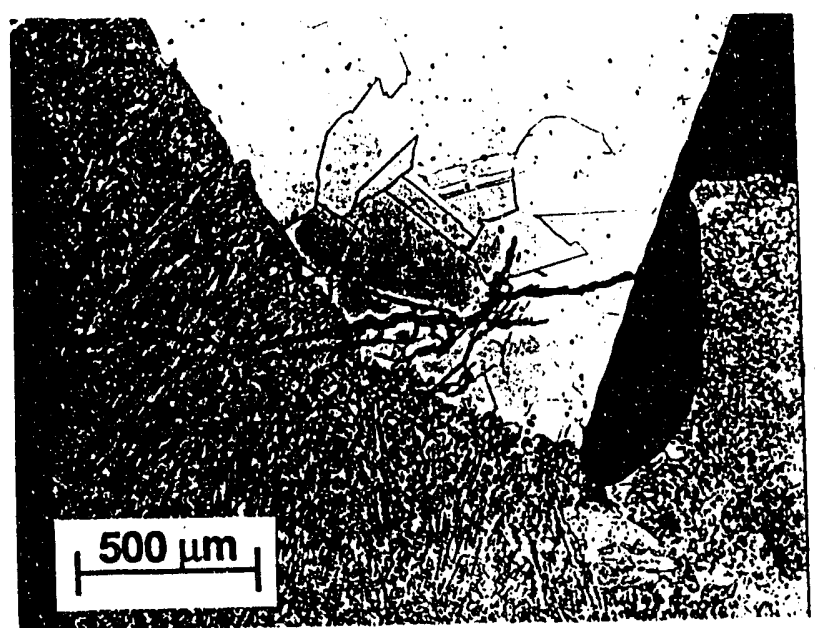

Fig. 3 - Transgranular crack that initiated in base metal in crevice region

residual stresses were apparently sufficient to drive TGSCC in this environment even in the absence of a crevice. At another location, relatively shallow TGSC.C originated at geometrical discontinuities in the weld bead.

Subsequent seal weld failures have been repaired with an Inconel 625 weld overlay, and a video inspection is made of the welds during each plant outage to detect any additional failures. Because these components are located in a high radiation field, these inspections and repairs must be done remotely.

Thermal Fatigue of a BWR RecirculationPump Shaft. The thermal fatigue cracking of main coolant pump shafts has become a significant and recurrent problem in both BWR and PWR nuclear power plants (8. 12). These pumps circulate reactor coolant at temperatures of about $288^{\circ} \mathrm{C}$ (550F) and are equipped with elastomer seals that must be maintained at about 55 to $65^{\circ} \mathrm{C}\left(130\right.$ to $\left.150^{\circ} \mathrm{F}\right)$. ᄂ Thermal fatigue cracking of the shaft typically occurs where the seal cooling water mixes with the hot reactor coolant. The analysis to be described here illustrates this type of failure.

The shaft to be analyzed came from a BWR recirculation coolant. pump that had been disassembled after $\approx 20,000$ hours of service. It was fabricated of Type 316 stainless steel, and a $\mathrm{Cr}$ plating had been applied over a portion of the shaft length to enhance resistance to galling during installation. The impeller was removed from the shaft at the plant, and a dyepenetrant inspection of the shaft was performed. This inspection revealed numerous cracks, primarily axial in orientation, immediately above the position where the impeller fits on the shaft. This location corresponds to the region where the BWR coolant at $288^{\circ} \mathrm{C}\left(550^{\circ} \mathrm{F}\right)$ mixes with the seal purge cooling water at $\approx 57^{\circ} \mathrm{C}\left(135^{\circ} \mathrm{F}\right)$. A complete failure analysis was requested. 


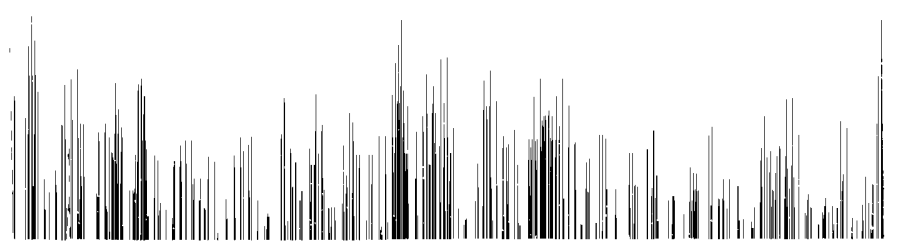

Fig. 4 - Axial cracks on recirculation pump shaft revealed by dye penetrant examination

The shaft was given a preliminary chlorofluorocarbon decontamination at the plant and was subsequently scrubbed with deionized water after its arrival at ANL. These procedures removed most of the loose activity, and the residual fixed activity was measured at $<10 \mathrm{mR} / \mathrm{hr}$ gamma and $\approx 400 \mathrm{mR} / \mathrm{hr}$ of beta. This unusually high level of fixed beta activity required that eye protection be worn when working with the component. More aggressive decontamination procedures were avoided to prevent damage to the shaft surface and, in particular, to any cracks that might be present.

A dye-penetrant examination was performed after decontamination, and typical results are shown in Fig. 4. The relief groove at the end of the shaft keyway is visible, and extensive cracking was evident around the entire circumference of the shaft in the vicinity of this groove. The cracks were relatively uniform in length, with a typical length of 13 to $19 \mathrm{~mm}$ ( 0.5 to $0.75 \mathrm{in}$.). They were typically spaced $\approx 6 \mathrm{~mm}(0.25 \mathrm{in}$.) apart on this side of the shaft and slightly farther apart on the opposite side. Of the approximately 75 cracks detected, essentially all were axial in orientation except for the few small circumferential components seen in Fig. 4.

A diffuse wavy circumferential line marking the lower boundary of the $\mathrm{Cr}$ surface plating may also be seen in Fig. 4 immediately above the relief groove. The region above this line is plated, and a portion of the cracking may be seen to lie within this region. The shaft was sectioned circumferentially near the center of the relief groove. This cut intersected the majority of the axial cracks near their midpoint. A second cut was then made $\approx 20 \mathrm{~mm}$ ( 0.75 in.) above the first, producing a disc-shaped slice that contained approximately half the length of the majority of the cracks present. This
Fig. 5 - Metallographic cross section of cracked region in BWR recirculation pump shaft

slice also included most of the boundary between the $\mathrm{Cr}$ plated and unplated portions of the shaft.

Two pie-piece segments, each of which included $\approx 50 \mathrm{~mm}$ ( 2 in.) of the shaft circumference, were cut from this slice and again examined by dye penetrant to determine the depth of the cracking. The typical depth was found to be $\approx 2$ to $3 \mathrm{~mm}$ (0.08 to 0.012 in.), and the maximum depth observed was $\approx 4 \mathrm{~mm}$ (0.16 in.). Optical metallography showed the cracks to be transgranular and straight, and most exhibited very little branching (Fig. 5). At higher magnifications, the crack tips were seen to be sharp, and the cracks were relatively free of oxide. In a few instances, moderate crack branching was observed, with oxide-filled secondary cracks. The $\mathrm{Cr}$ plating apparently did not contribute to or influence the nature of the cracking. No significant grain boundary sensitization of the shaft material was observed, and the ASTM grain size was typically 2 to 3 .

Scanning electron microscope (SEM) fractography was performed on two crack fracture surfaces. These specimens were prepared by cutting out crack segments and carefully trimming them so that the crack extended almost entirely through the cut piece. The pieces were then broken open to expose the fracture surfaces, including the crack-tip regions. The fracture surfaces were examined both before and after cleaning ultrasonicaily and with acetate replica stripping to remove any oxide and surface deposits. These cleaning procedures significantly improved the level of detail that could be observed.

The principal feature to be noted on the fracture surfaces was the presence of regions containing striations suggestive of fatigue. Virtually all of these striation-containing regions were observed within about 0.5 to $0.7 \mathrm{~mm}(0.020$ to 0.030 in.) of the crack tip. Presumably, at greater distances 
from the crack tip, the surface surfaces had been exposed to the environment for a sufficient length of time that the striations were obliterated. Striation spacing was typically about 0.5 to $1 \mu \mathrm{m}$.

Energy-dispersive X-ray analyses of selected areas of the fracture surfaces were performed before the surfaces were cleaned. The heavy deposit on much of the uncleaned surface was found to contain low-to-moderate levels of $\mathrm{P}, \mathrm{Si}$, and sometimes $\mathrm{S}$ and $\mathrm{Ca}$, in addition to the metallic elements $\mathbf{F e}$, $\mathrm{Cr}$, and $\mathrm{Ni}$ that would be expected.

It was concluded that the cracking observed on the pump shaft was produced predominantly by thermal fatigue, though stress corrosion cracking may have made a minor contribution in some regions. This conclusion is supported by the appearance of the cracks, most of which were relatively straight, had sharp tips, and were generally free of gross oxide buildup. It is further supported by the presence of apparent fatigue striations on the fracture surfaces, particularly in the crack tip regions. In addition, the relatively uniform orientation, spacing, and depth of the cracks suggests that the cyclic stresses responsible for the fatigue were thermal in nature. Finally, the service conditions of the shaft were conducive to thermal fatigue.

Several strategies have been developed to deal with this problem. The pump shafts are being monitored for cracks using mechanical vibration and mechanical resonance tochniques, and cracks are weld repaired as they are discovered. In some cases, the transition region of the pump cover has been modified to reduce the thermal gradient responsible for the cyclic stresses. In addition, the surfaces of new and repaired shafts are being shot peened to produce residual compressive stresses before they are placed into service.

Nickel Leaching in Pump Seal Wear Rings. The final failure to be described here is representative of several that have been seen by the author in cemented WC wear rings used in BWR pump seals. These wear rings are typically $\approx 250 \mathrm{~mm}$ ( $10 \mathrm{in}$.) in diameter and $\approx 15 \mathrm{~mm}(0.6 \mathrm{in}$.) wide, and they are fabricated of WC particles cemented in an $\mathrm{Ni}$ matrix. The rings ride on a very thin film of water against a matching graphite ring surface, and proper sealing requires extremely close tolerances on flatness and surface finish. Several failures of these rings have occurred in which the WC wear ring sealing face has become grooved and roughened. In some cases, fine regularly spaced radial cracks are present on the failed surface.

Figure 6 shows the sort of damage observed on the sealing face of a failed ring. The circular grooves and surface roughening seen on this face have a maximum depth of $\approx 130 \mu \mathrm{m}(0.005 \mathrm{in}$.), which is far in excess of the design tolerance on flatness for this surface. The fine parallel radial cracks mentioned above are also visible.

A metallurgical cross section through this region of surface roughening reveals the microstructure seen in Fig. 7. A porous cracked layer $\approx 20 \mu \mathrm{m}(0.001$ in.) thick is seen here, though in some regions its thickness was as great as

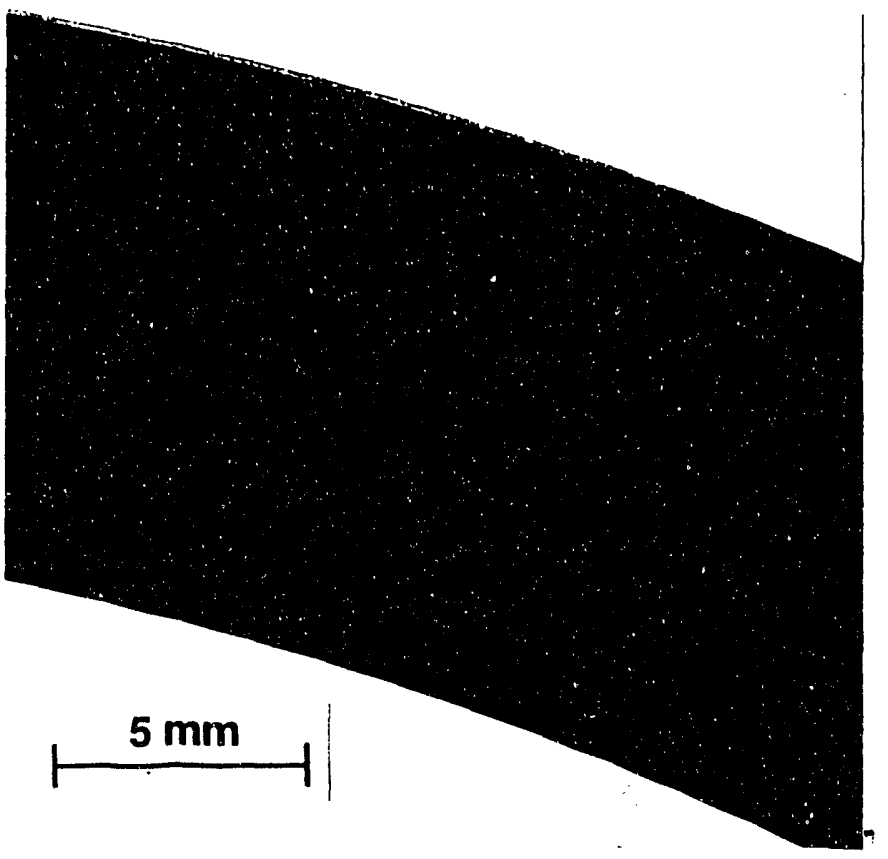

Fig. 6 - Damage observed on sealing face of failed wear ring

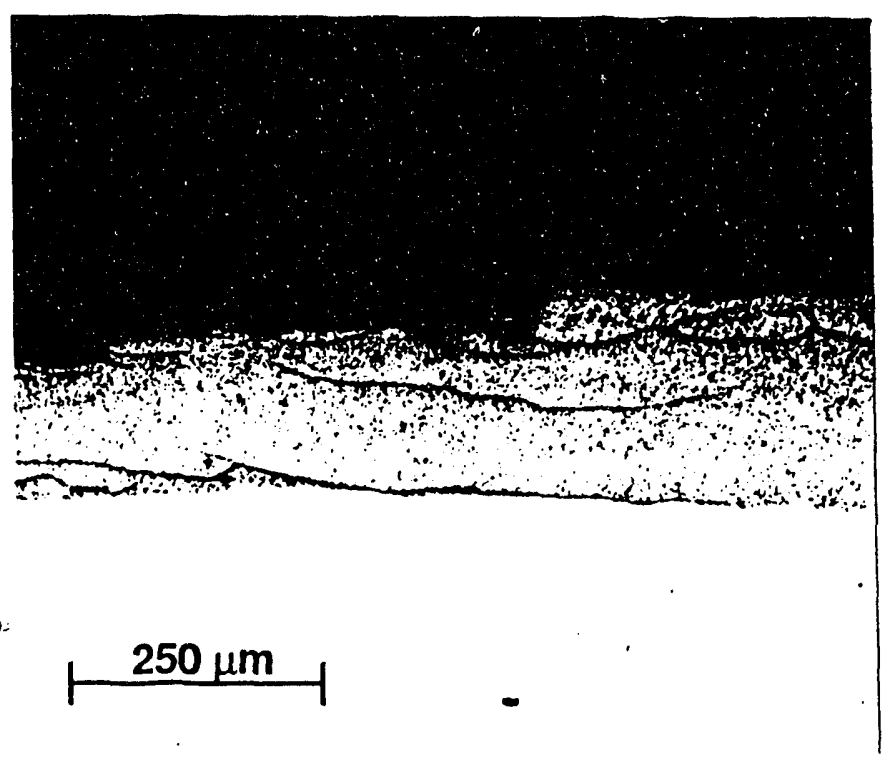

Fig. 7 - Ni-depleted porous regions (light gray area with cracks) present at damaged surface of failed wear ring

$\approx 150 \mu \mathrm{m}$ (0.006 in.). Energy-dispersive $X$-ray analyses reveal that these porous regions are depleted in $\mathrm{Ni}$. The $\mathrm{Ni}$ binder phase is apparently dissolving or being leached out of the composite, leaving a porous mass of WC particles that are rather easily dislodged. This process leads to the surface roughening and grooving observed, and further damage is produced by the abrasive action of the extremely hard WC particles. The fine cracking appears to be caused by thermal stresses created by the heating of the ring after surface 
roughening and the resulting breakdown of the lubricating water film.

The corrosion rate of $\mathrm{Ni}$ in a high-purity nuclear reactor coolant environment containing less than $0.02 \mathrm{ppm}$ dissolved oxygen has been experimentally determined to be about 2.5 to $5.0 \mu \mathrm{m} / \mathrm{yr}$ ( 0.1 to $0.2 \mathrm{mils} / \mathrm{yr})$ under dynamic conditions (13). However, other data have indicated that substantially greater corrosion rates can be expected under conditions of high dissolved oxygen (13), such as may occur in BWR coolant trapped in a crevice. In addition, it has been observed (14) that surface passivation of $\mathrm{Ni}$ may not occur in acidic and neutral water at temperatures in excess of $100^{\circ} \mathrm{C}\left(212^{\circ} \mathrm{F}\right)$. Some acidification of the solution trapped in the crevice between the wear rings is possible under static conditions because of hydrolysis effects and the buildup of impurity species in the crevice. Loss of passivation by the $\mathrm{Ni}$ would leave it more susceptible to general corrosion and to galvanic corrosion in contact with the mating graphite ring.

The solution to this problem appears to be the use of an alternate material for the wear ring. The other commonly used binder phase in cemented WC composites is Co, but its use in nuclear plants is precluded because of concerns about Co dissolution in the coolant and subsequent activation in the reactor core to ${ }^{60} \mathrm{Co}$. Monolithic ceramic wear rings are presently being explored as an altemative to cemented WC.

\section{Summary}

Failed components from nuclear power generating stations have been successfully handled and analyzed for a number of years with the procedures described here. Relatively simple decontamination procedures are generally sufficient to reduce the radioactivity of these components to safe levels for subsequent examination and analysis. Where these simple procedures are not satisfactory, more aggressive chemical procedures can be employed, though at the risk of damage to the component surfaces. Two of the analyses summarized here deal with failure modes commonly observed in the industry, i.e., IGSCC of BWR coolant piping and thermal fatigue of BWR recirculating pump shafts. The remaining two failures, namely TGSCC of PWR primary system components and leaching of the Ni binder phase in a cemented WC pump seal wear ring, represent less commonly observed modes of corrosive failure.

\section{References}

1. "World Nuclear Industry Handbook," p. 11, Nuclear Engincering International, Surrey, U. K. (1992).
2. Bradbury, D., M. G. Segal, R. M. Sellers, T. Swan, and C. J. Wood, "Development of LOMI Chemical Decontamination Technology," Electric Power Rescarch Institute Report EPRI NP-3177, (July 1983).

3. Shaw, R. A. and M. D. Naughton, in Proc. Second Int. Conf. on Water Chemistry of Nuclear Reactor Systems, Bournemouth, U. K., British Nuclear Energy Society, London (1981).

4. "Ionizing Radiation Exposure of the Population of the United States," National Council on Radiation Protection and Measurements, NCRP Report no. 93, Bethesda, MD (1987).

5. Cheng, C. F., J. Nucl. Mat., 56, 11-33 (1975).

6. Klepfer, H. H., "Investigation of Cause of Cracking in Austenitic Stainless Steel Piping," General Electric Company Report NEDO-21000-1 (July 1975).

7. Danko, J. C., pp. 181-188 in Proc. Conf. on Materials in Nuclear Technology, Huntsville, Ont., Canada, Sept. 29-Oct. 2, 1982, American Society for Metals, Metals Park, OH (1983).

8. Marston, T. U. and R. L. Jones, pp. 3-9 in Proc. Fifth Int. Symp. on Environmental Degradation of Materials in Nuclear Power Reactors-Water Reactors, Aug. 2529, 1991, Monterey, CA, American Nuclear Society, La Grange Park, IL (1992).

9. Cowan, R. L., C. C. Lin, W.-J. Marble, and C. P. Ruiz, pp. 50-58 in Proc. Fifth Int. Symp. on Environmental Degradation of Materials in Nuclear Power Reactors--Water Reactors, Aug. 25-29, 1991. Monterey, CA, American Nuclear Society, La Grange Park, IL (1992).

10. Diercks, D. R. and S. M. Gaitonde, pp. 136-146 in Proc. Conf. on Materials in Nuclear Technology, Huntsville, Ont., Canada, Sept. 29-Oct. 2, 1982, American Society for Metals, Metals Park, OH (1983).

11. Ruther, W. E., W. K. Soppet, and T. F. Kassner, Corrosion 44, 791-799 (1988).

12. Griesbach, T. J. and J. M. Weiss, "Evaluation of Main Coolant Pump Shaft Cracking," Electric Power Research Institute Report EPRI TR-100154, Tier 1 (Feb. 1992).

13. Friend, W. Z., "Corrosion of Nickel and Nickel-Base Alloys," pp. 43-44, John Wiley and Sons, New York (1980).

14. Shreir, L. L., "Corrosion, Vol. 1: Metal/Environment Reactions," pp. 4:109-4:110, Newnes-Butterworths, London (1976). 

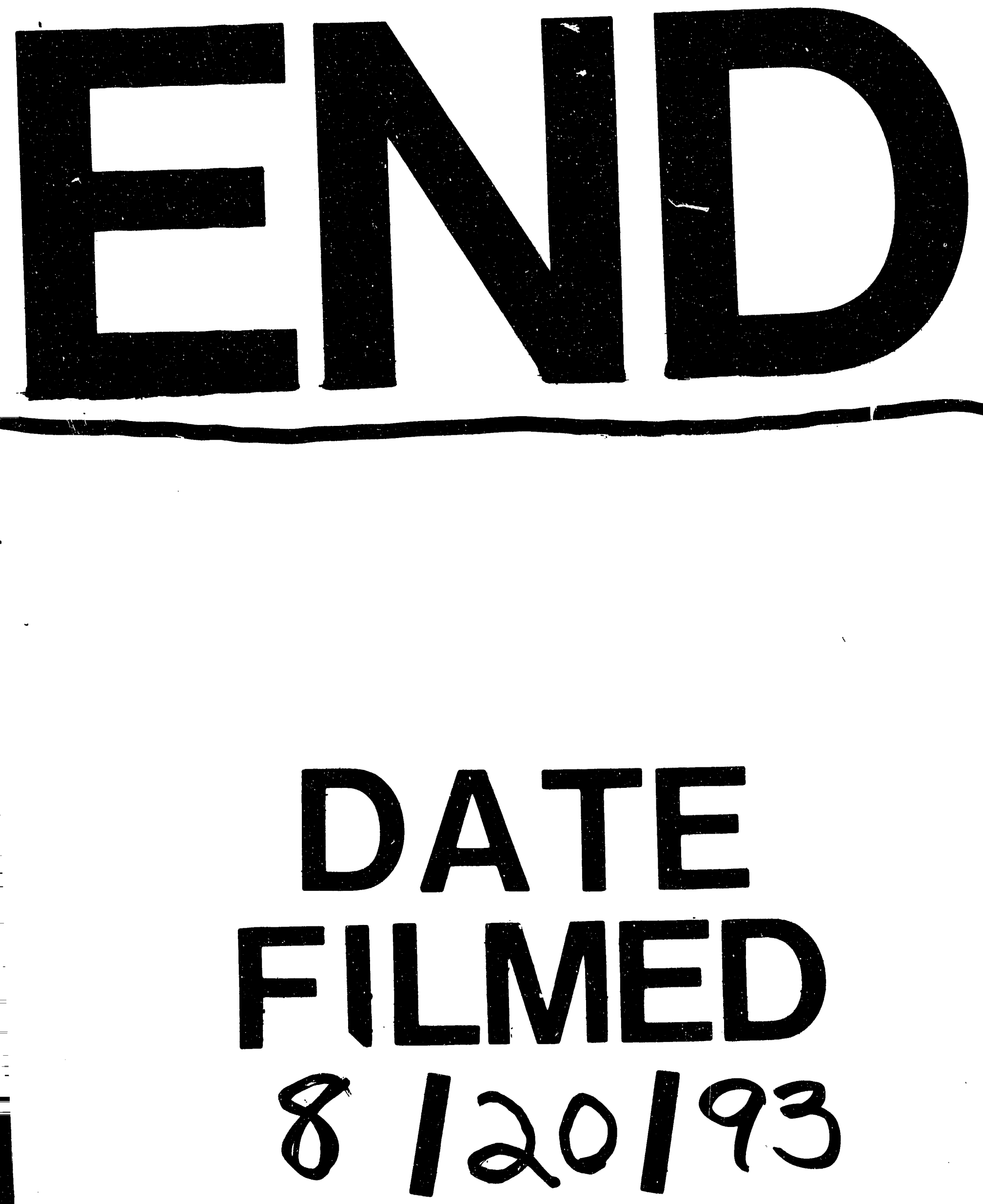
